EPiC Series in Computing
Volume 52, 2018, Pages 82-99
$\begin{aligned} & \text { ICT4S2018. 5th International Conference on Informa- } \\ & \text { tion and Communication Technology for Sustainability }\end{aligned}$

\title{
Towards a sustainable business model for smartphones: Combining product-service systems with modularity
}

\author{
Alice Frantz Schneider ${ }^{1}$, Sepideh Matinfar ${ }^{2}$, Eoin Martino Grua ${ }^{3,5}$, Diego \\ Casado-Mansilla ${ }^{4}$, and Lars Cordewener ${ }^{5}$ \\ ${ }^{1}$ Department of Informatics \\ University of Oslo \\ Oslo, Norway \\ 2 Ericsson Research \\ Stockholm, Sweden \\ sepideh.matinfar@ericsson.com \\ 3 Department of Computer Science \\ Vrije Universiteit Amsterdam \\ Amsterdam, The Netherlands \\ e.m.grua@vu.nl \\ ${ }^{4}$ DeustoTech-INTERNET \\ University of Deusto \\ Bilbao, Spain \\ dcasado@deusto.es \\ ${ }^{5}$ Software and Services (S2) group \\ Vrije Universiteit Amsterdam \\ Amsterdam, The Netherlands \\ lars. cordewener@gmail.com
}

\begin{abstract}
Based on the Sustainable Development Goals introduced by the United Nations and on the circular economy concept, ICT providers are adapting to become more sustainable. Some assess the $\mathrm{CO}_{2}$ emissions in the whole life cycle, while others propose to use renewable energies during manufacturing and assembling. In contrast with the current smartphone business models that rely on ongoing patterns of production and consumption, this paper proposes a more sustainable approach by combining product modularity, Product-Service Systems (PSS), and design for attachment. With a modular design, it becomes easier to repair the product or to replace parts, allowing for an extended lifespan. In combination with PSS, we propose that the modules, when no longer used by one customer, return to the market to be reused by another one. Lastly, we discuss the impact of the users' behaviour through emotional bond, personalization, and technology appropriation as predictors of attachment to the product and consequently an extended lifespan. Through comparing case studies and using Life Cycle Assessment to calculate the $\mathrm{CO}_{2}$ equivalent emissions, we argue that our approach would directly reduce the environmental impact of the smartphone on the production phase, which accounts for most of the emissions throughout its life cycle.
\end{abstract}




\section{Introduction}

The activities of the large and increasing world population are exploiting natural resources while a large part of the population is still struggling for basic survival needs. This points out the need for a more sustainable management of resources' production and consumption, in order to fulfill the requirements of an ever-increasing population, while preserving our natural resources.

In 2015, United Nations members and leading development institutions established the Sustainable Development Goals (SDGs) [45] for a global development framework. The SDG framework consists of 17 goals, 169 targets and 230 indicators covering a broad range of aspects for sustainable development. Among them, goal number 12 - Ensure sustainable consumption and production patterns - is directly related to our study, as well as goal number 13 - Take urgent action to combat climate change and its impacts. Based on this framework, it is clear that a more sustainable approach towards the current widespread electronics business model is required.

Some state the need to shift towards a more circular economy (CE) concept, which focus on a restorative system. This latter term is referred in one of the most popular definitions of Circular Economy (CE) stated by the Ellen Mac Arthur foundation [1], which says that $\mathrm{CE}$ "refers to an industrial economy that is restorative by intention; aims to rely on renewable energy; minimizes, tracks, and hopefully eliminates the use of toxic chemicals; and eradicates waste through careful design". To show this circular design, they offer the model shown in Figure 1.

This concept suggests the efforts for using all the materials of a value chain at the optimum level. Any intermediary output that cannot be used in the current chain could enter into another to be used there. As it is suggested by several studies, circular economy scenarios and corresponding business models would lead to reductions in $\mathrm{CO}_{2}$ emissions $\left(\mathrm{CO}_{2} \mathrm{e}\right)$ compared to business as usual [5]. As example, 2015 reports from Green Alliance and Trucost [44] asserted a huge potential within circular economy for cutting the carbon footprint of mobile devices by up to $50 \%$ with a complete recovery of raw material and precious metals that can increase benefits up to 10 billion dollars.

Product design is one of the priority areas within circular economy. European legislations for eco-design of ICT products mandate product design to make it easier for dismantling, reusing, and recycling electronic displays [18]. Some proposals in this direction focus on facilitating recycling, such as avoiding welding or gluing of particular components, or marking presence of cadmium or mercury and plastic parts [18].

Even though there are initiatives being implemented, the current widespread smartphone business model still relies on high patterns of production, consumption and discard. Compared to such prevailing life cycle, leaning towards a circular model that includes reuse in favor of disposal presents a series of benefits. In line with the CE, this paper has the main objective to analyze how an approach combining modularity, Product-Service System (PSS) business models and design for attachment could lead towards a sustainable business model for smartphones. For that, we apply a multiple case study methodology based on secondary data.

We compare $\mathrm{CO}_{2}$ e of modular and non-modular smartphones by using Life Cycle Assessment (LCA) methods and present the PSS business model by bringing examples of its successful implementations for other products. We further discuss modularity and how such design may impact the smartphone's life cycle. The user's behavior is also addressed as an important aspect towards achieving a more sustainable business model. Factors such as emotional bond, personalization and technology appropriation are further highlighted as predictors of willingness 


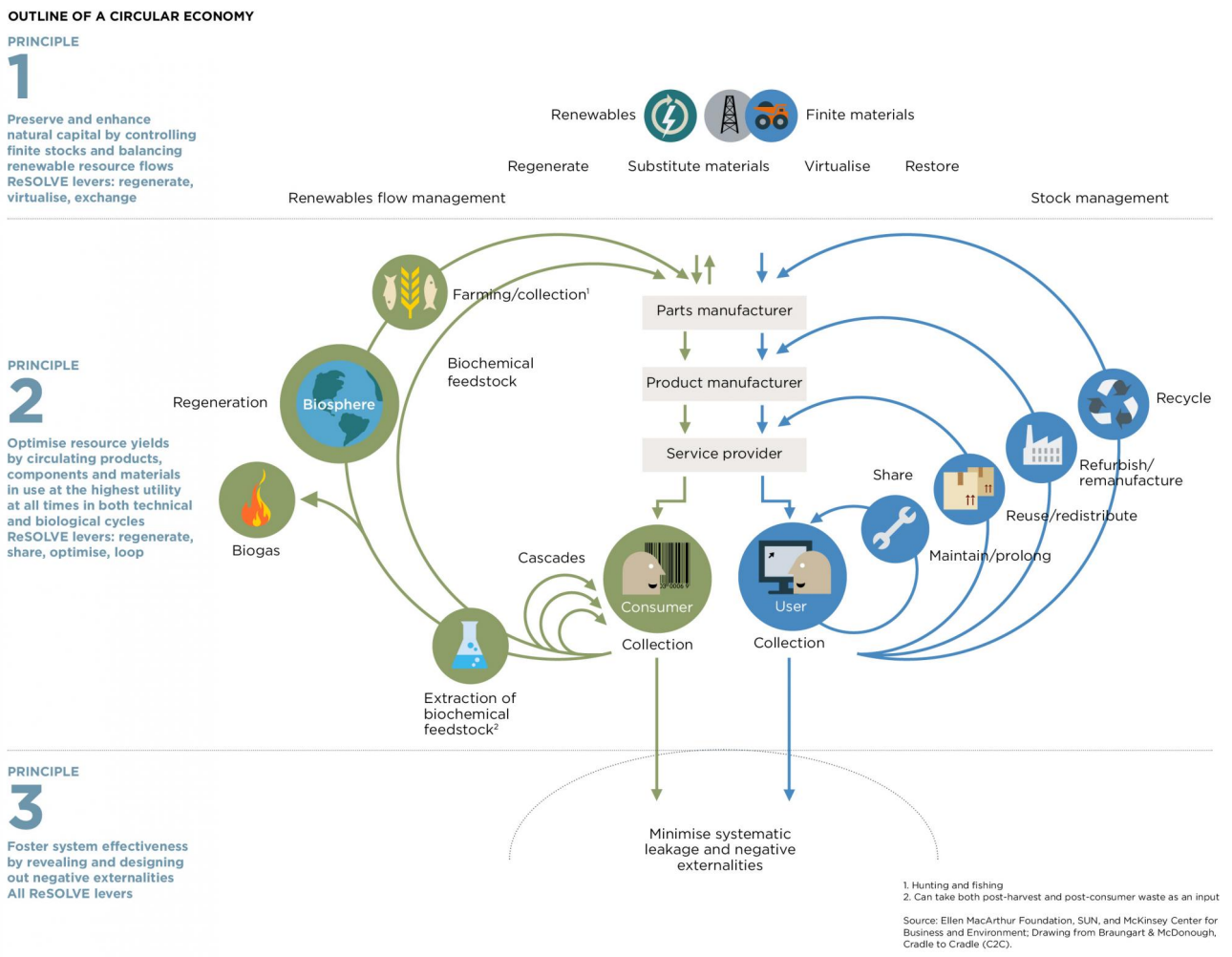

Figure 1: Circular economy model, taken from the Ellen Mac Arthur Foundation [1]

to keep personal devices for longer. In the discussion section, we focus on the implementation potential of the suggested approach for smartphones, in addition to pointing out the possibilities of applying it to other products.

\section{The Product-Service System Business Model}

Although lacking a theoretical basis in both business and economic theory [47], business models are important tools for value creation and are part of any business. The business model guides the company on how the value is created and delivered to the customer.

There are several business models currently used by companies, such as the razor blade and the freemium model [47]. Among the many existing, there are critiques to how the vast majority incentivise consumerism. With the finite resources of our planet and severe environmental impacts that high levels of consumption entail, relying on such models proves to be unsustainable and goes on the opposite direction of the SDGs described before. Finding business models in which sustainability and profitability go hand in hand presents a challenge, as well as an opportunity for driving innovation in the corporate environment.

The PSS are emergent business models that consider the environmental impacts. In opposi- 
tion to the focus on the product, these models combine the product with the service they provide. "This approach can have significant environmental benefits in terms of reducing the volume of products manufactured while maintaining or increasing profits for the company through service provision" [29, p. 885]. Hence, the company relies on the service it provides and a high turnover of products is not necessary to maintain its profitability.

Particularly when it comes to mobile phones, the current business models show to be very unsustainable. According to Boons and Ludeke-Freund, the mobile telephony is a locked-in model that has high ecological impact due to mainly excessive resource use [4]. In addition, there are also negative social impacts, such as the working conditions in the extraction of metals phase.

There is an evident need for changing the way smartphones are commercialized. Although not addressing modularity, Lee et al. propose the PSS to be applied for mobile phones. They emphasize the need for a combination of such models with the design of the product towards recyclability [26]. The precious metals could be thus more easily extracted, generating value back to the system after being recycled.

In addition to the PSS, Maxwell and Van der Vorst bring the example of the computer as a service in combination with modularity [29]. They highlight that modularity would extend the operational life of the product. Such combination of the modular electronic offered as a service is the one we propose to be applied for smartphones, together with strengthening design for attachment. Both aspects are discussed in the next sessions.

By defending the PSS business model to be applied for smartphones, we address the high turnover of devices predominant in our society and tackle several approaches against obsolescence (e.g. reuse through transferability, repair and reuse of materials; and longevity through functionality and motivation [40]). Considering that the company providing the service remains the owner of the device, such goes back into the loop whenever the user wants to change its subscription. In our proposed approach, this also involves changing modules, as is discussed further on. With that, devices or modules that are no longer used by a particular segment of consumers remain to be used by another segment.

\section{Similar case studies}

The following subsections bring up brief case studies of companies that work with the PSS business models. Although these are not focused on smartphones, they provide insights on how such models may be applied to different products.

\subsection{The lighting service}

One of the first and most notable examples of planned obsolescence is the limiting of the light bulbs life span in the 1920s. The long lasting light bulbs started to be perceived as an economic disadvantage at the time and, as a result, a secret cartel was established to limit their life span. Light bulbs that would last for up to 2500 hours had to be adapted to last no longer than 1000 hours [10]. Since the 1920s, many examples of planned obsolescence gained strength, considering that with the business models applied it would be unsustainable, from an economic perspective, to have low levels of consumption.

Philips represents an interesting case concerning more sustainable lighting through service. With the PSS, the company offers a series of services focused on reducing waste while preserving its profitability, which include professional services with audit and consulting, life cycle services, and managed services. Within the managed services, one option is the light as a service, in 
which the consumer pays for the used light instead of the lighting equipment. The consumer does not own the product, but has the benefits of the service provided by the lighting [36].

An example of such service is the pay per lux solution in the office of the National Union of Students (NUS) in the United Kingdom, as a response to students looking for more sustainable solutions for their institutions. With a 15 year fixed price that includes design, equipment and installation, NUS does not own any lighting equipment, instead renting it from Philips. An interesting aspect is that, if consumption is more than expected, NUS gets a fee reimbursed, which motivates Philips to provide the most energy-efficient service possible. The company retains the ownership through the whole life cycle, thus being responsible for taking the products back at the end-of-life [37].

\subsection{The carpet leasing}

The PSS is also applied by the carpet manufacturer Desso, founded in 1930 in the Netherlands and now active in more than 100 countries. The company applies the Cradle to Cradle model $(\mathrm{C} 2 \mathrm{C})$, a biomimetic approach concerning the circularity of materials in the system. All materials are perceived as nutrients and, being organic or technical, should flow in a waste-free manner and in the most efficient way possible [30].

The company offers a carpet leasing service option, including installation, cleaning, maintenance, and removal at the end-of-life [11]. The consumer does not own the product, thus Desso removes and recycles the carpet when the consumer does not want the product/service anymore, closing the loop towards a circular economy.

\subsection{The washing machine subscription service}

Another example of the PSS is the Dutch company Bundles, which has its business based on high quality home appliances subscription services. The company began in 2014 with the aim of aligning business with the circular economy concept. Primarily with the focus on washing machines, currently the company also offers tumble dryers and dishwashers.

One of the main principles of Bundles is that using sustainable appliances may be cheaper than owning low-quality appliances. In this line, the company provides a high quality product as a service, which makes it possible for people to afford to use a longer lasting machine, even though they would not be able to buy such appliance [6].

With Bundles, the consumer pays for the service per month, depending on the amount of washes required. The idea of the service is also to motivate consumers to use the machine in a more conscious way, with guidelines to lower energy, detergent and water use. The installment, maintenance and repairs are included in the service [7]. As the ownership of the machine remains with Bundles, whenever the subscription ends, the equipment goes back to the company.

\section{Modularity}

With the increasing environmental challenges and several problems arising from high levels of consumption, modular design has been attracting increased attention. Nevertheless, the basic idea of modularity may be tracked to the older concept of near-decomposability. Introduced by Simon in 1962, it proposes that all systems have a near decomposable architecture divided into several parts organized in an hierarchical way [42]. As such, the interactions of elements in the same part are more intense than the ones belonging to different parts, even though a certain 
level of interdependence is always present. The concept is directly linked with modularity by looking at different parts/modules of a system and levels of interconnection.

Modularity may be applied to several fields and has different definitions. When addressed as a design principle, Campagnolo and Camuffo categorize the literature review in three units of analysis - product design modularity, production systems modularity and organizational design modularity, being the first one the most addressed in research [8]. For this paper, we also discuss modularity from a product design perspective.

In the case of smartphones here addressed, we understand modularity as a set of swappable hardware parts that may be customized while obtaining an expanded lifetime with maximum possibility of repair and minimum generation of electronic waste. Therefore, when the user wants to switch or upgrade a particular component, it is possible to do so by changing a specific module, without the need to change the whole device.

\subsection{Examples of modular smartphones}

The modular smartphone started receiving attention in 2013 with the Phonebloks concept [21]. Created by a Dutch designer, Phonebloks focused on reducing waste by designing a phone with separated blocks to be attached to a main board. This way, the different blocks could be changed whenever needed or wanted for either replacing broken ones or for upgrading them without the need of changing the whole device. In addition, Phonebloks allows for personalization, since the consumer may choose the most suitable blocks according to its needs.

The Phonebloks is a concept project to be disseminated among mobile phone producers towards the design of their devices. After its launch, the concept quickly gained worldwide attention and soon a cooperation began with Google through project Ara and Motorola - at the time a Google subsidiary. The project's idea was to build the hardware based on a frame to which single modules would be added, just as proposed by Phonebloks. Project Ara had a configurator app to help with the multi-dimension configuration in different layers - from the endoskeleton, to choosing the specific modules and to technical information such as storage size and battery life. The configurator app was also designed with a Phone Maker feature, in order to help those who were not able to choose which modules to add in the endoskeleton [22]. Despite the efforts and years of commitment, Project Ara got cancelled in September 2016 [21], after the smartphone design was almost ready to be launched.

Besides Project Ara, other companies are working on modular phones from the Phonebloks concept. The Phonebloks official website [21] points out also to ZTE Eco-Mobius, Xiaomi Magic Cube, PuzzlePhone, Fonkraft and Fairphone 2 as companies contributing to a modular future.

Fairphone is a Dutch social company that produces the modular smartphone Fairphone 2. The company focuses on minimizing social and environmental impact across the phones' life cycle through a long-lasting design, fair materials, good working conditions, reuse and recycling [2]. The company launched its first model in December 2013, followed by the Fairphone 2 in December 2015. Fairphone 2 focuses on fairness in different spheres (e.g. manufacturing with conflict free tin and tantalum; and fair design based on modularity to support repair and recycling). In addition, the company gives special importance to transparency by challenging social norms, such as giving full disclosure of its supply chain and tackling unsustainable practices across it [49].

\subsection{Main considerations of a modular smartphone}

A Modular product design (MPD) has a series of positive impacts. In terms of the environment, MPD increases manufacturing efficiency, reduces inventory cost and addresses the demand 
towards mass customization [28]. Furthermore, one important benefit of a modular smartphone is the extended durability [41]. Thus, considering that is possible to upgrade or change the specific module when needed, the consumer is able to keep a modular smartphone for longer than with a traditional model, avoiding or lengthening to the maximum the device's obsolescence.

By upgrading only the necessary modules, the lifespan of the smartphone is extended and the generation of electronic waste at the end-of-life (EoL) phase is minimized. In addition, the modular design focuses on reparability, an essential step in the mobile phone lifecycle when aiming at sustainability. When divided into modules, it becomes easier to separate the damaged parts to repair or exchange them for new ones when needed. This is particularly the case of Fairphone 2, which focuses on a design for reparability with individual building blocks easily accessible by opening its case. Indeed, iFixit, a company leading the 'teardowns' of consumer devices gave to Fairphone 2 the highest repairability score among all the market's phones ${ }^{1}$.

Other benefits are in terms of mass customization (MC) and personalization. MC has the aim of offering services and goods that meet the various customers needs, while coping with high levels of efficiency to address mass production [22, 48]. At the same time, personalization allows certain levels of flexibility for consumers to choose the service or goods most suited to their aims. Modularity is an essential part of MC strategy [22] that allows consumers to obtain personalized products more aligned with what they seek. In addition, it may reflect in an emotional bond between the consumer and the product, which is discussed further on.

\section{Life-cycle Assessment}

In order to measure the environmental impact of smartphones in a controlled and reproducible fashion, a standardized process should be implemented. One method that considers the quantitative aspects of a product's life cycle is the Life Cycle Assessment. From gathering the raw materials, to user operation, to finally recycling the parts or the inevitable disposal of the product, each aspect of the product is considered and evaluated to reach a total cost in $\mathrm{CO}_{2}$ equivalent emissions for the entire life cycle. Whereas LCA is a common method for assessing the environmental impacts for electronic products, with guidelines establishing rules to ensure the validity of LCAs [13], such as the ITU-L.1410 and RES/EE-EEPS14, some voices are reluctant to embrace LCA as a whole. Ehrenfeld [14] offers a critical look at the pros and cons for the usage of the LCA method, while Svensson and Ekvall [46] draw into question the validity of comparing two products using LCA.

Since the LCA process is already well known, in this section we instead focus on its shortcomings and possible improvements. Then we outline the intended method of comparing the proposed approach with the current smartphone model using LCA.

\subsection{Previous works}

In 2013 Ercan wrote about the Global Warming Potential (GWP) impact of smartphones [15], based upon a previous study of a feature phone performed by the same institute in 2008 . They analyzed a Sony Xperia T using an LCA methodology, looking at every aspect of the life cycle from material gathering to the disposal of the device and even the included manual. From their study it can be seen that the production phase of the device has the most impact on $\mathrm{CO}_{2} \mathrm{e}$ [15]. Thus, it is interesting to note that a model proposing less load during the production phase through reuse of components would be expected to have less of an impact. In 2016, Ercan et

${ }^{1}$ https://www.ifixit.com/Teardown/Fairphone+2+Teardown/52523 
al. continued to investigate different impact categories for smartphones, including references to several studies on smartphones they performed in the past [16].

However, others have noted how looking at LCA results from one aspect of the life cycle can be misleading. Moghaddam et al. provide an example in their work based upon laptops and their energy consumption. As a whole, laptops were found to be $40 \%$ more efficient than desktop computers, while the use phase showed an increase in consumption for the particular model used for comparison [32]. From the same study there should also be focus on the impact of management on the results of LCA. In contrast to most other fields, ICT and its implementation of software has to consider the management and intelligent use of said software as part of LCA. This is as of yet not properly represented in the results, however, further adding to the misleading nature of the results [32].

Prunel et al. looked at the environmental labels of smartphones and how to use LCA when determining the label of a product [39]. They also investigated known issues and difficulties when using LCA, offering solutions in the form of standardizing the LCA format.

Güvendik wrote a thesis on the environmental impact of circular economy scenarios using LCA on smartphones [20]. The work presents the LCA methodology, concept of circular economy, and the impact smartphones have using this model through a case study of Fairphone. Fairphone [2], having a modular design that allows for less production, implements a variation of circular design that this paper aims to build upon by adding the reusability of each device and further reducing the impact of the production phase.

Despite the content of their study aligning well with our intended work, it is important to note that Güvendik does not address the shortcomings of LCA as we have presented here. While their conclusions might still be valid through the case study of Fairphone, we should note that the results might be skewed without considering these shortcomings.

The last example of this review comes from Suckling and Lee [43]. They do not focus directly on the LCA methodology, however, they do corroborate the previously established findings of the production phase having the most environmental impact when network and service usage are not taken into consideration. By investigating the environmental impact of smartphones, they focus on the various aspects of their life cycle and note how most impact is made during the processing of materials and the production.

\subsection{Importance}

Based on previous work, it has already been shown how focusing on a model for smartphones that reduces the emissions of the production phase can reduce the environmental impact of smartphones [15, 20, 43]. An interesting topic to investigate is to take the case study of Fairphone with its modular design to further introduce the concept of selling smartphones as a service, while keeping into account the various shortcomings and difficulties that come with relying solely on LCA for metrics and drawing conclusions.

\section{Emissions}

In the following section, we address the carbon footprint of both a modular and a non-modular smartphone. The $\mathrm{CO}_{2} \mathrm{e}$ values were all gathered from either [38] or [17]. In fact, the emission values for the Fairphone 2 (used here as example for the modular smartphone) are all taken from [38], whilst the values used for the non-modular smartphone are all from [17]. In the first of the following two subsections, we analyze in more detail such $\mathrm{CO}_{2} \mathrm{e}$ values and demonstrate how the modular smartphone is more sustainable in this aspect. In the second subsection, we 
compare the Fairphone 2 sold as a product with our proposed approach and explain how ours would achieve the same, if not better, $\mathrm{CO}_{2} \mathrm{e}$.

\subsection{Fairphone 2 vs non-modular smartphone}

Table 1: Fairphone $2 \mathrm{CO}_{2}$ e over a 3 and a 5 year LCA

\begin{tabular}{|l|l|lr|l|}
\cline { 2 - 4 } $\begin{array}{l}\text { Fairphone } \\
\text { emissions }\end{array}$ & $\begin{array}{l}3 \text { year } \mathrm{LCA} \\
\text { (no repairs) }(\mathrm{Kg} \\
\left.\mathrm{CO}_{2} \mathrm{e}\right)\end{array}$ & $\begin{array}{l}5 \text { year } \\
\text { (with } \\
\text { pairs) }(\mathrm{Kg} \\
\left.\mathrm{CO}_{2} \mathrm{e}\right)\end{array}$ & $\begin{array}{l}\text { percentage } \\
\text { difference }\end{array}$ \\
\hline Total & 43.85 & 52.39 & $19.48 \%$ \\
\hline Production & 38.98 & 43.56 & $11.75 \%$ \\
\hline EoL & -1.11 & -1.14 & $2.70 \%$ \\
\hline Use & 5.98 & 9.97 & $66.72 \%$ \\
\hline
\end{tabular}

Table 2: Non-modular smartphone $\mathrm{CO}_{2}$ e over a 3 year LCA and a calculated 5 year LCA

\begin{tabular}{|c|c|c|}
\hline $\begin{array}{l}\text { Non- } \\
\text { modular } \\
\text { smartphone }\end{array}$ & $\begin{array}{l}3 \text { year } \mathrm{LCA} \\
(\text { no repairs })(\mathrm{Kg} \\
\left.\mathrm{CO}_{2} \mathrm{e}\right)\end{array}$ & $\begin{array}{l}\text { calculated } 5 \\
\text { year LCA (with } \\
\text { repairs)(Kg } \\
\left.\mathrm{CO}_{2} \mathrm{e}\right)\end{array}$ \\
\hline Total & 56.7 & 67.36 \\
\hline Production & 49.8 & 55.65 \\
\hline EoL & -0.3 & -0.31 \\
\hline Use & 7.2 & 12.00 \\
\hline
\end{tabular}

Table 1 reports the values found in [38] on the $\mathrm{CO}_{2} \mathrm{e}$ of the Fairphone 2 over an LCA of 3 years with no repairs taken into account and an LCA of 5 years, which has repairs added in the Production phase for the $\mathrm{CO}_{2} \mathrm{e}$ value. Given that our study considers the scenario of a 5 year LCA with repairs and that in [17] the only values reported are for a 3 year LCA with no repairs, we have calculated the percentile difference of the two LCA scenarios within the Fairphone 2 data. The percentile differences have then been used to calculate an approximation of what the emissions over a 5 year LCA with repairs for the non-modular smartphone would be (values can be seen in table 2).

To explain why we believe that it is fair to use such percentages, we have to examine each component that makes the total $\mathrm{CO}_{2} \mathrm{e}$. Starting with 'Use', we can safely assume that for both the Fairphone 2 and the non-modular smartphone, the emissions caused by the use of the product are fairly linear, therefore the percentile difference would be of the same value for both models.

For 'Production' and 'EoL', the reason the numbers vary between the 3 year LCA and the 5 year LCA scenarios is due to the repairs accounted for in the 5 year LCA. Here the scenario is different from the above mentioned 'Use' phase. In this case, we can assume that the emissions of repairs for a Fairphone 2 are lower than the ones for a non-modular smartphone. This would be due to the modular nature of Fairphone 2 and its policy of making repairs easily accomplished by the customer (which cuts on transportation costs). But, given that we have no estimate of what the repair would emit in the non-modular smartphone here considered and that using 
Table 3: Comparison of $\mathrm{CO}_{2} \mathrm{e}$ of Fairphone 2 with a non-modular smartphone

\begin{tabular}{|l|l|l|}
\cline { 2 - 3 } $\begin{array}{l}5 \text { year LCA } \\
\text { with repairs } \\
\text { comparison }\end{array}$ & Faiphone $2\left(\mathrm{Kg} \mathrm{CO}_{2} \mathrm{e}\right)$ & $\begin{array}{c}\text { Non-modular } \\
\text { smartphone }\left(\mathrm{Kg} \mathrm{CO}_{2} \mathrm{e}\right)\end{array}$ \\
\hline Total & 52.39 & 67.36 \\
\hline Production & 43.56 & 55.65 \\
\hline Eol & -1.14 & -0.31 \\
\hline Use & 9.97 & 12.00 \\
\hline
\end{tabular}

the percentile difference from the Fairphone 2 would, if anything, make our calculated value lower than its real emissions, we remain with the percentile difference knowing it is likely a conservative estimate.

As a conclusion, we compare the emissions from the Fairphone 2 and the non-modular smartphone (as seen in table 3) and can safely conclude that, over the 5 year LCA considered, the Fairphone 2 is the most sustainable in terms of $\mathrm{CO}_{2} \mathrm{e}$.

\subsection{Fairphone 2 vs our proposed approach}

Now that we have argued why the Fairphone 2 is more sustainable in terms of $\mathrm{CO}_{2} \mathrm{e}$ than a non-modular smartphone for the 5 year period, we would like to argue why our presented approach would at minimum achieve the same emissions and, at best, be more sustainable than the Fairphone 2 sold as a product.

In addition to the already shown difference that modularity has and looking back at Section II, offering smartphones as a service instead of as a product owned by each individual reduces the impact of the 'Production' even more. With this being the primary source of $\mathrm{CO}_{2} \mathrm{e}$, and the already established benefits of such business models [29], we defend that a large scale reduction in the 'Production' would contribute to a more sustainable approach for smartphones.

A benefit that our approach has over Fairphone 2 sold as a product lies in the repairability. Whenever a device comes back from a user, there is a chance that it has become damaged. However, the damaged part might not be included in the latest subscription that has been requested. Therefore, the rest of the phone that was returned, and is still fully operational, can be put back into service without the broken part being immediately replaced. This of paramount relevance if we take into account that a piece of research by Echegaray stated that around $40 \%$ of the replaced mobile phones are kept at homes' shelves without any use [12].

\section{The impact of design for attachment on PSS}

We understand the smartphone as part of a highly complex system. In the same line, Joshi and Pargman propose a socio-ecological approach towards technology by building systems more aligned with the finite resources of our planet [23]. They critically discuss the Fairphone case and how it relates to changing behaviour of the designer, producer and consumer. With this same lens, we consider the complexity of different ways of thought in the smartphone life cycle system.

The presented approach for expanding the devices' longevity relies on three pillars; namely PSS, modularity, and willingness to maintain the smartphone as long as possible (i.e. enhancing the device's attachment). Whereas the two former pillars depend on the producers and the 
carriers (service providers), the latter highly depends on the end users' behaviour and their connection with the digital product (including the brand).

What is important in our proposed approach is that end-users may desire to invest time and money in the product upkeep or refurbishment, instead of asking for a replacement when something goes wrong. Thus, "increasing product durability on its own is unlikely to overcome the very significant psychological, emotional and social factors which underpin the rapid churn of products in the modern throwaway society" [12].

Increasing the attachment to smartphones is important for the environment since statistical data from existing reports and literature claim that the average life-span of mobile phones is close to two years [34] due to planned, perceived, and forced obsolescence ${ }^{2}$. Hence, the number of mobile phones manufactured is increasing substantially, with an enormous environmental impact if we take into account that around $80 \%$ of the $\mathrm{CO}_{2} \mathrm{e}$ occur during the manufacturing phase $[15,43]$.

In the following paragraphs we provide three main factors that can impact product longevity and willingness to be maintained: emotional bond, personalization, and technology appropriation. Whereas there are other factors that should not be overlooked, e.g. the price paid for the phone, we have focused only on the triad of factors because they are predictors of the device's attachment.

According to Chapman [9], waste or replacement may be seen as a symptom of failed subject/object relationship. The author suggests strategies for emotionally durable objects. People may feel deeply attached to their favorite possessions, whereas other possessions are less significant. When a person develops an emotional bond with a product, this product acquires meaning beyond the functional. The strategies suggested that can be applied for smartphones include new, alternative genres of objects or greater user experience, which engage users on deeper levels and over longer, more rewarding, periods of time. Existing literature on emotional bonding and digital product design suggests that this factor may result in an increase of the attachment to the product, which in turn is a predictor of the product's lifespan [19, 33, 27]. Emotional attachment can occur at multiple levels, usually from a combination of several ones, such as sentimental relevance, dependability, timelessness, usability, and graceful aging.

Another factor that may increase the preservation of mobile phones is personalization. Based on the definition of Blom [3], product personalization is defined as a process that defines or changes the appearance or functionality of a product to increase its personal relevance to an individual. Personalization can enhance the products ease of use and reflect their personal or group identity ("me, my mobile, and my identity"). Furthermore, product customization helps consumers to recognize a product as ones own. According to Mugge et al. [33], by personalizing a product, a consumer directs time, energy, and attention to it. The authors conducted a study where they showed that product personalization by investing time and effort in the process can stimulate emotional bonding with the product, therefore extending its lifetime. The modularity concept presented in our approach is directly linked to personalization. Not only because endusers may select custom pieces that make the phone to link closer to them, but because they can upgrade certain parts of the device in order to conserve a sense of continuous novelty which is appreciated in some segments of the population (e.g. young adults).

The final selected factor that can affect the maintenance of the smartphone for longer is the technology appropriation and the sense of technology ownership [24]. It stresses the importance of empowering and involving the user in the process of maintaining and taking care

\footnotetext{
${ }^{2}$ The former obsolescence is due to the unsustainable product design by companies that impair the repairability of smartphones; the second is due to the marketing of consumerism, social norms and throwaway culture; and the latter is due to the rapid change on the technology market, in which it could happen that a certain hardware still functioning has to be replaced because there is no software upgrades for it anymore.
} 
of the digital product in order to boost self-efficacy, satisfaction, and pride. In this regard, appropriation aims to develop feelings of psychological ownership with respect to the digital technology itself. Individual appropriation is experienced as a subjective and virtual form of customization or self-design that is usually studied as a formal, explicit process and involves the consumer applying their own individual resources, such as their need for control, aesthetic appreciation or self-efficacy, to resources provided by the manufacturer, including design tool kits and customizable interfaces. The modular phone approach followed in ours can spark these senses by allowing users to perform repairs or hardware upgrades either alone or supported by a community around the product (examples of these existing communities are the repair cafe ${ }^{3}$ and Fairephone's Angels ${ }^{4}$ ).

\section{Discussion}

Based on a multitude of case studies, three different aspects to improve the sustainability of smartphones as a whole were assessed to analyze how an approach combining them could lead towards a sustainable business model for smartphones. From that, this paper proposes a more sustainable approach for the smartphone market than the currently widespread.

First and foremost, this resulted in the understanding that the production phase of the smartphone has the largest influence on the $\mathrm{CO}_{2}$ equivalent emissions of its complete life cycle. Hence, methods aiming to reduce the impact of this phase may bring strong improvements in terms of sustainability.

The first aspect of our proposed approach is modularity. By comparing two smartphone case studies, one from Fairphone [20] and one from Sony Ericsson [15], and assuming that both rely on the same parameters for the LCA calculation, the LCA for the 5 year time-frame shows a clear difference in the emissions produced over their life cycle, as shown in Table 3. This data shows the difference between a modular and a non-modular design, with the modular phone having less $\mathrm{CO}_{2} \mathrm{e}$ compared to the non-modular, in every stage of the life cycle for the period of comparison.

The second aspect considered is the business model. We suggest implementing the PSS business models for smartphones, which differ from the current widespread model by not selling the product itself, but the service provided for using the device. We have shown several case studies that already implemented such models, as well as highlighted the potential behind them through ascertaining how unsustainable the current widespread model is [4].

The last aspect looked at, namely design for attachment, is considered an additional value of combining the previous two aspects. Specifically, by allowing the users to pick services based on their needs and receiving products that match such services is claimed to improve the users' attachment to these particular devices. Instead of receiving products that are closest to what they desire, but might have less or more features than actually required, our proposed approach would allow users to pick services that fit them best and, thus, be motivated to continue using these services for as long as possible.

In addition to discussing the potential of implementing the suggested approach for smartphones, this section intends to show the potential for other products as well. We aim to convince businesses of the potential worth of our approach by comparing it to previous studies, as well as drawing parallels to different products that have already adapted a similar format. This section also focuses on the methods used in this paper and describes possible limits to the validity of our claims.

\footnotetext{
${ }^{3}$ https://repaircafe.org/en/

${ }^{4}$ https://forum.fairphone.com/t/angel-the-angels-program-local-support-by-community-members/33058
} 


\subsection{Implementation potential}

As previously shown, some companies have already implemented similar approaches to our proposed one. Looking back at the material covered in section II, PSS business models have already been considered for several products. Of particular interest is the proposal of [29], who describe an approach very similar to ours, intended for computers. While the pay per lux solution and the Bundles service offers are both PSS business models examples, they do not promote modularity. That is not to say their efforts are not important for our proposal; studies aimed at their models, and the practical implementation of such, prove that PSS models have a place being used for different products.

However, since [29] specifically include modularity in their work, the comparison between them and our work is more applicable. Despite not having a direct implemented example to link to, each aspect of our proposed approach has already seen success separately. The various PSS case studies previously discussed and the modularity as described in Fairphone have been assessed and shown to be more sustainable than alternatives. Therefore, a combination of these two aspects should prove to further improve the sustainability while retaining profits for the producers.

In addition to the modularity and the PSS business model, we have highlighted as well the importance of design for attachment. By combining these three concepts, we claim to be possible to achieve a more sustainable approach for the way smartphones are not only commercialized, but also designed and produced.

The PSS business models make interesting for companies to design long-lasting products and, thus, minimize production. By combining the PSS with modularity, we propose an approach that works towards closed cycles, promoting repair and reuse to its maximum. Since the ownership of the device remains with the producers, it becomes interesting for them to have products that last as long as possible and are easy to be reused and repaired. Whenever a consumer wishes to change a certain module in its smartphone, such module would go back to the company and, if still working, be reused by another consumer that is looking for such module in its subscription modality. If not working, the module would go to be repaired and, only if not possible, to the recycling phase.

\subsection{Limitations}

First and foremost, it should be mentioned that no calculations or LCA were performed on a live example of our proposed approach. The values used are taken from previous LCA and case studies, before being compared for our own purposes. Considering that they are taken from different sources, we cannot guarantee that the $\mathrm{CO}_{2} \mathrm{e}$ were calculated with the same parameters and, thus, the comparison of the LCA has limitations, only serving as a guideline.

For such comparison, it was chosen to use data based on a lifecycle of 5 years. The data from the Fairphone case study provided this information directly, while the study from Sony Ericsson (for the non-modular phone) did not. As such, we have applied the same growth of each LCA phase that was observed in the Fairphone' study to the data from Sony Ericsson. However, due to the difference in production phase; namely that replacing or repairing the Sony Ericsson phone would require more resources and transportation costs than the equivalent in Fairphone, it is reasonable to assume that the provided data in our calculations would be even higher for the Sony Ericsson device.

It is important to highlight here that LCA and $\mathrm{CO}_{2} \mathrm{e}$ of smartphones differ according not only to modularity, but other aspects, such as design and composition within the modular and the non-modular phones. The comparison here, by analyzing only one model of each, is rather 
limited and cannot be generalized. The goal of comparing the LCA of these two models was to present the reader with a broad idea of the extend to which such impact might differ.

Due to complexity, when addressing the $\mathrm{CO}_{2}$ e for the LCA calculations, we have not taken into account the network and service usage, otherwise the environmental impact of the 'Use' phase would differ [43]. Our comparison is also limited for taking into account only the $\mathrm{CO}_{2} \mathrm{e}$, which is one of the many impact categories to consider [31]. A more detailed comparison, involving different models of smartphones and accounting for the network and service usage in combination with other factors besides $\mathrm{CO}_{2} \mathrm{e}$, is suggested so to have a more complete analysis.

While introducing the concept of design for attachment and the value that customization has for users to increase the use phase during a smartphone life cycle, we were unable to find concrete data to quantify this phenomenon. The different studies and results show that the effect exists, however there is no concrete data to confirm it. As such, our claim that the personalization of a modular device service would increase the likelihood of consumers sticking to their device for longer than with a non-modular device cannot be substantiated with concrete data and further study is suggested also on this aspect.

\section{Conclusions}

This paper proposes a more sustainable approach to be considered and further applied for smartphones than the currently widespread; one combining modularity, PSS business models and design for attachment. Overall, the modular smartphone presents different paths towards more sustainable devices, considering that its design promotes repairability of the whole device and replacement of only the damaged modules. Nevertheless, we have identified several challenges in applying the modular design of smartphones to the large scale.

The first challenge is connected with industries and their current business models, particularly when it comes to technology, which mostly rely on ongoing patterns of production and consumption to maintain profitability. Strategies of obsolescence are put into practice, such as planned obsolescence (with certain components that stop working after a period of time), and forced obsolescence (such as the product not being compatible with software upgrades). If based on such business models, the concept of a modular phone, with a focus on repair and reuse to achieve a long-lasting product does not make sense from an economic perspective.

The second challenge in applying modular smartphones to the large scale relates to the consumers and their behaviour towards maintaining devices for long periods of time. A modular design demands more critical raw materials for production than a non-modular one due to the need of connectors [41]. Besides the environmental impact in the production phase, this incurs into higher production costs, which is translated into products that are more expensive. With high patterns of consumption towards disposable products predominant in our society, spending more is not always appealing for consumers, even though they could keep the product for longer and it would make sense financially on the long run. Therefore, a modular phone only makes sense, both in terms of economy and environment, if the consumer keeps the device for long.

Furthermore, it is important to consider the unexpected user behaviour towards the replacement of modules. Modularity opens for the possibility of a rebound effect in the sense of the consumer changing modules more frequently than actually needed [49, 41, 25]. Depending on such frequency, the environmental impact may become more intense than of the non-modular smartphones, meaning that, in this scenario, the modular phone would be less sustainable than the non-modular.

In our proposed approach, we have considered such challenges by proposing a combination of three aspects, namely PSS, modularity and design for attachment. By establishing such 
combination, it becomes interesting for companies to work against strategies of obsolescence, thus making sense to have a modular phone with an extended life cycle. With design for attachment, we address the importance of involving the consumer in the life cycle of the product with practices such as emotional bond, personalization and appropriation.

Considering that all modules end with the company after use, our approach also addresses one of the biggest challenges in the smartphone life cycle; the management of such devices at the EoL. Besides more sustainable in terms of production and use, it promotes more efficient levels of collection of EoL devices for recycling, which is one of the big challenges for recycling. The value of the scrap materials and precious metals would be retained by the producers, allowing them to better address the extended producer responsibility in terms of managing the electronic waste.

On a broader extent, our approach promotes design for repairability and recyclability. Considering the ownership remains to the ones producing the device, it becomes interesting for them to have devices that can be easily repairable and be put back into the market. Business models relying on high patterns of production are not needed in this case and repair gains strength. Going towards closed circles, the device goes back to the producer through a reverse logistic chain at the EoL phase to be recycled. Thus, it becomes relevant for the producer to put on the market devices that are more easily recyclable. Initiatives towards designing smartphones that are more easily dismantled and in which the materials can be better separated in the recycling process so to achieve high levels of material recovery with minor environmental impact, are expected in our proposed approach.

As it was shown through several case studies presented, there are already initiatives using the three aspects individually. Nevertheless, the extend to which they are combined is limited and, for the specific case of smartphones, the current prevailing model still goes in the opposite direction, mainly due to a divergent logic of thought among the actors involved. Corroborating Patrignani, only closing cycles in not enough to address sustainability; we also need to reflect on the speed of these cycles [35].

Our paper goes in line with the circular economy model here presented and the speed of technology. Its main contribution relies on pointing out to the importance of connecting actors in the different phases of the smartphone life cycle when working towards a sustainable business model, as well as on discussing a possible approach for doing so. By focusing on modularity, we involve mainly the designers and producers. Further with PSS, we connect the carriers (service providers) as important actors in the chain. Finally, by discussing about design for attachment, we highlight the importance of the user.

By combining three aspects, we have presented a more sustainable approach towards the current widespread smartphone business model, one that directly reduces the environmental impact of the production phase and, consequently, the whole smartphone life cycle. Both through decreasing the number of smartphones produced, as well as being able to replace specific parts instead of manufacturing an entire new device. In addition, we claim to be viable for companies to implement such approach, as users are more likely to gain attachment to their product and service, therefore prolonging their use and reaching long-term profits. On top of that, our approach proposes an alternative with focus on more sustainable smartphones, while still leading to profitability for the companies producing them.

\section{Acknowledgments}

We would like to thank the ICT4S Summer School, for the knowledge sharing and for enabling us to establish connection. In addition, special acknowledgment should be made to Maja van 
der Velden and Pernilla Bergmark, for the reviews provided to enhance this paper.

\section{References}

[1] Building blocks of a circular economy. https://www.ellenmacarthurfoundation.org/ circular-economy/building-blocks. Accessed: 2017-10-02.

[2] Fairphone. https://www.fairphone.com/en/. Accessed: 2017-10-02.

[3] Jan Blom. Personalization: a taxonomy. In CHI'OO extended abstracts on Human factors in computing systems, pages 313-314. ACM, 2000.

[4] Frank Boons and Florian Lüdeke-Freund. Business models for sustainable innovation: state-ofthe-art and steps towards a research agenda. Journal of Cleaner Production, 45:9-19, 2013.

[5] Framework for implementing the principles of the circular economy in organizations. Guide. Standard, British Standard Institution, May 2017.

[6] Bundles. The bundles concepts. https://www.bundles.nl/en/about-us/. Accessed: 2017-10-8.

[7] Bundles. How it works. https://www.bundles.nl/en/how-it-works/. Accessed: 2017-10-8.

[8] Diego Campagnolo and Arnaldo Camuffo. The concept of modularity in management studies: a literature review. International Journal of Management Reviews, 12(3):259-283, 2010.

[9] Jonathan Chapman. Design for (emotional) durability. Design Issues, 25(4):29-35, 2009.

[10] C. Dannoritzer. Pyramids of waste - the lightbulb conspiracy, 2010.

[11] Desso. Carpet leasing. http://www.desso-businesscarpets.com/services/carpet-leasing/. Accessed: 2017-10-8.

[12] Fabián Echegaray. Consumers' reactions to product obsolescence in emerging markets: the case of brazil. Journal of Cleaner Production, 134:191-203, 2016.

[13] Quantis ECOFYS. Bio,ict footprint: Pilot testing on methodologies for energy consumption and carbon footprint of the ict-sector, european commission, luxembourg. Technical report, Luxembourg, Tech. Rep. SMART.

[14] John R Ehrenfeld. The importance of lcaswarts and all. Journal of Industrial Ecology, 1(2):41-49, 1997.

[15] Elif Mine Ercan. Global warming potential of a smartphone: Using life cycle assessment methodology, 2013.

[16] Mine Ercan, Jens Malmodin, Pernilla Bergmark, Emma Kimfalk, and Ellinor Nilsson. Life cycle assessment of a smartphone. In 4 th International conference on ICT for sustainability, 2016.

[17] Mine Ercan, Jens Malmodin, Pernilla Bergmark, Emma Kimfalk, and Ellinor Nilsson. Life cycle assessment of a smartphone. In 4 th International conference on ICT for sustainability, 2016.

[18] European Commission. Report from the commission to the european parliament, the council, the european economic and social committee and the committee of the regions on the implementation of the circular economy action plan. http://ec.europa.eu/environment/circular-economy/ implementation_report.pdf, 2017.

[19] Maria Fossdal and Arild Berg. The relationship between user and product: Durable design through personalisation. In DS 83: Proceedings of the 18th International Conference on Engineering and Product Design Education (EESPE16), Design Education: Collaboration and CrossDisciplinarity, Aalborg, Denmark, 8th-9th September 2016, 2016.

[20] Merve Güvendik. From smartphone to futurephone: assessing the environmental impacts of different circular economy scenarios of a smartphone using lca. 2014.

[21] Dave Hakkens. Phonebloks. https://phonebloks.com/. Accessed: 2017-10-27.

[22] Stephan Hankammer, Ruth Jiang, Robin Kleer, and Martin Schymanietz. From phonebloks to google project ara. a case study of the application of sustainable mass customization. Procedia CIRP, 51:72-78, 2016. 
[23] Somya Joshi and Teresa Cerratto-Pargman. On fairness \& sustainability: Motivating change in the networked society. Advances in Computer Science Research, 2015.

[24] Colleen P Kirk, Scott D Swain, and James E Gaskin. Im proud of it: consumer technology appropriation and psychological ownership. Journal of Marketing Theory and Practice, 23(2):166184, 2015.

[25] Rafael Laurenti, Jagdeep Singh, Rajib Sinha, Josepha Potting, and Björn Frostell. Unintended environmental consequences of improvement actions: a qualitative analysis of systems' structure and behavior. Systems research and behavioral science, 33(3):381-399, 2016.

[26] Jacquetta Lee, James R Suckling, Debra Lilley, and Garrath T Wilson. What is valueand how can we capture it from the product value chain? In Sustainability Through Innovation in Product Life Cycle Design, pages 297-313. Springer, 2017.

[27] Alex Lobos and Callie W Babbitt. Integrating emotional attachment and sustainability in electronic product design. Challenges, 4(1):19-33, 2013.

[28] Junfeng Ma and Gül E Okudan Kremer. A systematic literature review of modular product design (mpd) from the perspective of sustainability. The International Journal of Advanced Manufacturing Technology, 86(5-8):1509-1539, 2016.

[29] Dorothy Maxwell and Rita Van der Vorst. Developing sustainable products and services. Journal of Cleaner Production, 11(8):883-895, 2003.

[30] William McDonough and Michael Braungart. Cradle to cradle: Remaking the way we make things. North point press, 2010.

[31] Åsa Moberg, Clara Borggren, Christine Ambell, Göran Finnveden, Fredrik Guldbrandsson, Anna Bondesson, Jens Malmodin, and Pernilla Bergmark. Simplifying a life cycle assessment of a mobile phone. The International Journal of Life Cycle Assessment, 19(5):979-993, 2014.

[32] Reza Farrahi Moghaddam, Fereydoun Farrahi Moghaddam, Thomas Dandres, Yves Lemieux, Réjean Samson, and Mohamed Cheriet. Challenges and complexities in application of lca approaches in the case of ict for a sustainable future. arXiv preprint arXiv:1403.2798, 2014.

[33] Ruth Mugge, Jan PL Schoormans, and Hendrik NJ Schifferstein. Emotional bonding with personalised products. Journal of Engineering Design, 20(5):467-476, 2009.

[34] Oeko-Institut. Resource efficiency in the ict sector. http://ow.1y/cyjR30g9a0S, 2016. Accessed: 2017-10-26.

[35] Norberto Patrignani. The challenge of ict long-term sustainability. Visions for Sustainability, (7), 2017.

[36] Philips. Managed services. http://www.lighting.philips.com/main/services/ managed-services. Accessed: 2017-10-8.

[37] Philips. Uk student movement is beacon of sustainability for wider society. https: //www.philips.com/a-w/about/sustainability/sustainable-planet/circular-economy/ light-as-a-service.html. Accessed: 2017-10-8.

[38] Marina Proske, Christian Clemm, and Nikolai Richter. Life cycle assessment of the fairphone 2. 112016.

[39] Damien Prunel, Etienne Lees-Perasso, Axel Roy, and Catherine Moulin. Environmental labelling of mobile phones: Lca standardisation process. In ICT4S, 2014.

[40] Christian Remy and Elaine M Huang. Addressing the obsolescence of end-user devices: Approaches from the field of sustainable hci. In ICT innovations for sustainability, pages 257-267. Springer, 2015.

[41] Karsten Schischke, Marina Proske, Nils F Nissen, and Klaus-Dieter Lang. Modular products: Smartphone design from a circular economy perspective. In Electronics Goes Green 2016+(EGG), 2016, pages 1-8. IEEE, 2016.

[42] Herbert A Simon. The architecture of complexity. In Facets of systems science, pages 457-476. Springer, 1991. 
[43] James Suckling and Jacquetta Lee. Redefining scope: the true environmental impact of smartphones? The International Journal of Life Cycle Assessment, 20(8):1181-1196, 2015.

[44] Sustainable Brands. More affordable devices lead to doubling of e-waste in china since 2010. https://tinyurl.com/y9cajg94, 2017. Accessed: 2017-3-1.

[45] Sustainable Development. Sustainable development goals. https://sustainabledevelopment. un.org/sdgs. Accessed: 2017-10-12.

[46] Göran Svensson and Tomas Ekvall. Lca-a fair and cost effective way to compare two products? Technical report, SAE Technical Paper, 1995.

[47] David J Teece. Business models, business strategy and innovation. Long range planning, 43(2):172194, 2010.

[48] Juha Tiihonen and Alexander Felfernig. An introduction to personalization and mass customization. Journal of Intelligent Information Systems, pages 1-7, 2017.

[49] Maja van der Velden. Design as regulation. In International Conference on Culture, Technology, and Communication, pages 32-54. Springer, 2016. 